\title{
Menggali Potensi Wisata Alam Untuk Kegiatan Sport Tourism Di Kabupaten Sleman Daerah Istimewa Yogyakarta
}

\author{
Wisnu Hadi ${ }^{1)}$, Atun Yulianto ${ }^{2)}$ \\ Perhotelan, Fakultas Ekonomi Dan Bisnis ,Universitas Bina Sarana Informatika \\ Jl. Ringroad Barat Ambarketawang, Gamping, Sleman, Yogyakarta ${ }^{1,2)}$ \\ E-mail :wisnu.wsh@bsi.ac.id ${ }^{1)}$, atun.aty@bsi.ac.id( ${ }^{2)}$
}

\begin{abstract}
Abstrak
Dalam dunia pariwisata banyak sekali jenis-jenis wisata salah satunya Sport Tourism atau wisata olah raga. Kabupaten Sleman salah satu contoh mempunyai potensi wisata alam yang dapat dipetakan untuk wisata olah raga atau sport tourism. Pada masa pandemi covid-19 dan pembatasan sosial terdapat kecenderungan masyarakat memanfaatkan waktu untuk berolahraga dengan tujuan meningkatkan imun, seperti jalan sehat, lari ataupun bersepeda ke spot-spot wisata yang tersebar diwilayah Yogyakarta. Tujuan penelitian ini adalah untuk menggali potensi wisata di Kabupaten Sleman sudah menyediakan fasilitas Sport Tourism. Dalam penelitian yang bersifat deskriptif kualitatif ini, peneliti mengangkat potensi wisata alam di Kabupaten Sleman yang memiliki wahana sport tourism. Hasilnya didapatkan data bahwa disisi utara terdapat lereng gunung Merapi tepatnya di bukit Klangon yang telah dikembangkan wisata olahraga berupa Mountain Bike untuk ajang kejuaraan lokal maupun tingkat nasional. Destinasi dikawasan wisata candi prambanan juga banyak digunakan untuk event nasional dan internasioanal sebagai wisata olah raga seperti marathon, road bike, jalan sehat, sepeda santai dan yoga. Disisi barat pada aliran sungai Progo yang mengalir di wilayah Kabupaten Sleman sudah dimanfaatkan juga untuk sport tourism olah raga arung jeram dan pada aliran sungai Opak di obyek wisata Lava Bantal Berbah Sleman juga digunakan untuk wisata river tubing dan sepeda santai. Kawasan lain yang tidak kalah menarik dalam mengembangkan sport tourism adalah perbukitan yang ada kecamatan Prambanan Sleman. Kawasan ini berada disisi timur Yogyakarta yang memiliki banyak destinasi wisata baik alam maupun sejarah seperti Candi Boko, Tebing Breksi dan Spot Riyadi. Kawasan wisata ini masih dapat dikembangkan lagi untuk kegiatan wisata olahraga yang menarik wisatawan baik nasional maupun internsional, seperti sport lari lintas alam, marathon, mountain bike, sepeda santai dan jalan santai dengan menjelajahi rute perbukitan yang melewati obyek wisata tersebut.
\end{abstract}

Kata Kunci : Potensi, Wisata Alam, Sport Tourism

\section{Exploring the Potential of Nature Tourism for Sport Tourism Activities in Sleman Regency Daerah Istimewa Yogyakarta}

\begin{abstract}
In the world of tourism, there are many types of tourism, one of which is sport tourism. One example of Sleman Regency has the potential for natural tourism that can be mapped for sports tourism or sport tourism. During the COVID-19 pandemic and social restrictions, there is a tendency for people to use their time to exercise with the aim of increasing their immunity, such as healthy walks, running or cycling to tourist spots spread across the Yogyakarta area. The purpose of this research is to explore the tourism potential in Sleman Regency which has provided Sport Tourism facilities. In this qualitative descriptive study, the researcher raised the potential of natural tourism in Sleman Regency which has a sport tourism vehicle. The results obtained data that on the north side there is a slope of Mount Merapi, precisely on the Klangon hill, which has developed sports tourism in the form of Mountain Bikes for local and national championship events. Destinations in the Prambanan temple area are also widely used for national and international events as sports tourism such as marathons, road bikes, healthy walks, relaxing bicycles and yoga. On the west side, the Progo river that flows in the Sleman Regency area has also been used for sport tourism, white water rafting and the Opak river at the Lava Pillow Berbah tourism object, Sleman is also used for river tubing and relaxing bicycles. Another area that is no less interesting in developing sport tourism is the hills in the Prambanan sub-district of Sleman. This area is located on the east side of Yogyakarta which has many natural and historical
\end{abstract}


tourist destinations such as Boko Temple, Breksi Cliff and Riyadi Spot. This tourist area can still be developed again for sports tourism activities that attract both national and international tourists, such as cross-country running sports, marathons, mountain bikes, leisurely bicycles and leisurely walks by exploring hilly routes that pass through these attractions.

Keyword : Potential, Nature Tourism, Sport Tourism

\section{PENDAHULUAN}

Pandemi virus Covid-19 yang melanda secara global memberi imbas ke segala bidang kehidupan sehingga menyebabkan pergerakkan manusia dari satu tempat ke tempat lain menjadi terhambat salah satunya adalah bidang pariwisata. Hampir diseluruh negara di dunia ini terdampak oleh wabah ini dan saat ini belum ada tanda-tanda menurun karena belum ada obatnya sehingga orang enggan bepergian ke luar daerah atau negaranya untuk tujuan berwisata.

Negara Indonesia sebagai negara yang terdampak wabah Covid-19 ini sampai saat ini mengalami kelesuan dalam kunjungan wisatawan baik lokal dan internasional hal ini dari Pusat Data dan Sistem Informasi Kementerian Pariwisata dan Ekonomi Kreatif Republik Indonesia bahwa selama tahun 2020 kunjungan wisatawan asing(wisman) hanya berjumlah 4.052.923 kunjungan atau mengalami penurunan sebesar $74,84 \%$ dibandingkan tahun 2019 yang berjumlah

\subsubsection{0 kunjungan.}

Untuk mengatasi persoalan tersebut pemerintah pusat dalam hal ini Kementerian Pariwisata dan Ekonomi Kreatif Republik Indonesia menggalakan program-program pemulihan ekonomi khususnya ekonomi wisata daerah dengan memberi isentif kepada pelaku wisata atau pemberdayaan desa wisata agar kesejahteraan ekonomi warganya. Para kepala daerah diminta untuk selalu mengkampanyekan daerahnya aman untuk dikunjungi dengan program kesehatan(prokes) sebagai senjata andalan untuk menarik wisatawan daerah atau nasional.

Selama pandemi Covid-19 bahwa kegiata wisata olahraga khususnya olah raga bersifat outdoor atau di luar ruangan menjadi trend atau mewabah seperti olahraga sepeda baik secara perorangan maupun kelompok. Kegiatan tersebut kebanyakan dilakukan di obyek wisata yang bersifat alam karena tujuan mereka mencari suasana yang aman dan nyaman.

Banyak obyek wisata di daerah menawarkan keindahaan, keunikanan dan budayanya kepada wisatawan selama masa Pandemi Covid-19 sebagai sarana menghilangkan kepenatan atau kebosanan karena terlalu lama dirumah atau sekolah serta bekerja dirumah. Pengelola obyek wisata menawarkan wisatawan untuk berwisata sambil berolahraga namun tetap menjaga keamanan wisatawan dari penularan penyakit ini dengan menerapkan prokes yang ketat.

Sport tourism sekarang menjadi andalan obyek wisata untuk menarik wisatawan untuk berwisata sambil melakukan kegiatan olah raga secara fisik dan rohani sehingga mereka akan mendapat tingkat kesehatan yang optimal karena dapat menikmati keindahaan alam yang alami karena dikelola dengan profeional.

Salah satu daerah yang mempunyai potensi wisata alam untuk kegiatan Sport Tourism adalah Kabupaten Sleman Daerah Istimewa Yogyakarta dimana keindahaan alam, keunikan serta budayanya sudah banyak terkenal keluara daerah atau mancanegara. Potensi wisata alamnya sudah banyak digali oleh pengelola atau pelaku wisata untuk menjadikan obyek wisata sebagai wisata yang berciri Sport Toursim. Dalam penelitian ini tujuan yang akan didapat nantinya mengenai data yang bersifat informasi tentang potensi-potensi destinasi wisata yang bersifat alam yang bisa menjadi tempat untuk wisata olahraga di ruang terbuka. Untuk itu peneliti tertarik melakukan penelitian tentang menggali potensi wisata alam untuk kegiatan Sport Tour di Kabupaten Sleman sehingga menjadi bahan studi dalam pengembangan wisata Kabupaten Sleman Daerah Istimewa Yogyakarta saat ini dan akan datang.

\section{KAJIAN PUSTAKA}

\section{Pariwisata}

Pembahasan pengertian pariwisata menurut para ahli banyak sekali namun dalam arti luas Pariwisata selalu identik dengan perjalanan. Sesuai dengan Undang-undang Republik Indonesia No 10 Tahun 2009 pengertian dari pariwisata adalah 
sebagai aktivitas melakukan perjalanan, baik yang dilakukan oleh individu ataupun kelompok. Namun tujuan mereka tidak lain untuk rekreasi, mempelajari keunikan yang ditawarkan oleh objek wisata atau sekedar untuk mengembangkan diri.

Arti lain menurut Kodhyat (1998, 4), pariwisata adalah sebagai perjalanan dari tempat satu ke tempat yang lain. Baik yang dilakukan secara perorangan, kelompok atau pun usaha. Dimana orang yang melakukan perjalanan wisata ini memiliki kepentingan untuk keseimbangan mental, misalnya mengurangi stress, menghibur diri dan refreshing.

\section{Potensi Dan Daya Tarik Wisata}

Pengertian potensi wisata menurut Mariotti dalam (Yoeti, 1983), adalah segala sesuatu yang terdapat di daerah tujuan wisata, dan merupakan daya tarik agar orang-orang mau datang dan berkunjung ke tempat tersebut(Samuel dan Anom, 2016). Pengertian yang sama tentang potensi wisata sebagai segala yang dimiliki oleh suatu daya tarik wisata dan berguna untuk mengembangkan industri pariwisata di daerah(Sukardi, 1998).

Sehingga potensi selalu identik dengan suatu daya tarik wisata yang menarik orang untuk berkunjung. Daya tarik menurut Kariza dan Diyah dibukunya Oka A. Yoeti (2009:166) sebagai apa saja yang dapat ditawarkan kepada mereka bila mereka datang berkunjung pada suatu negara atau daya tarik wisata tertentu.

\section{Sport Tourism}

Suatu kegiatan pariwisata selalu berkorelasi dengan industri pariwisata dan itu berbeda dengan pengertian pariwisata. Bahwa industri pariwisata lebih menekankan pada pemberian fasilitas dan kenyamanan di tempat wisata tersebut. Menurut Undang-Undang Republik Indonesia No. 10 Tahun 2009 industri pariwisata adalah kumpulan usaha yang bertujuan menghasilkan barang-jasa demi memenuhi kebutuhan dan kenyamanan wisatawan.

Salah satu industry pariwisata yang sedang dikembangkan adalah Sport Tourism karena kegiatan ini menjadi peluang bisnis sehingga menjadi tempat perputaran ekonomi bagi masyarakat suatu daerah. Menurut Nurida Finahari dkk di dalam Undang-Undang No 3 Tahun 2005 bahwa Sport Tourism atau olahraga rekreasi adalah olahraga yang dilakukan oleh masyarakat dengan kemauan dan kemampuan yang tumbuh dan berkembang sesuai dengan kondisi dan nilai budaya masyarakat setempat untuk kesehatan, kebugaran, dan kesenangan. Sport Tourism sebagai salah satu bentuk wisata minat khusus dalam dunia kepariwisataan dan banyak dikembangkan diberbagai daerah karena dapat mendongkrak wisatawan berkunjung.

\section{METODE PENELITIAN}

Dalam penelitian ini peneliti menggunakan jenis penelitian deskriptif kualitatif sehingga pemahaman penjelasan dan temuan akan dideskripsikan dalam bentuk uraian kalimat-kalimat sehingga hasil penafsiran secara kritis argumentatif berdasarkan dari data yang diperoleh dari hasil penelitiaan. Sejalan dengan pendapat Bogdan dan Taylor dalam (Moleong, 2003) bahwa metodologi kualitatif adalah sebagai prosedur penelitian yang menghasilkan data deskriptif berupa kata-kata tertulis atau lisan dari orangorang dan perilaku yang dapat diamati. Sehingga penelitian dikatakan sebagai penelitian yang tidak mengadakan perhitungan.

Dalam pengumpulan data peniliti melalui beberapa sumber yaitu sumber data primer berupa observasi terhadap obyek wisata alam yang mempunyai potensi Sport Tourism yang ada di Kabupaten Sleman Daerah Istimewa Yogyakarta. Kemudian sumber data yang bersifat sekunder berupa dokumen-dokumen yang sudah tersedia dan dapat diperoleh peneliti melalui dengan cara membaca, melihat dan mendengar. Data sekunder diperloleh melalui buku, website dan kepustaakaan yang berhubungan dengan potensi wisata alam untuk kegiatan Sport Tourism yang ada di Kabupaten Sleman Yogyakarta. Untuk analisa data dalam penelitian bersifat analisa deskriptif yang pengujiannya bertitik tolak dari data primer dan sekunder yang telah terkumpul kemudian menguraikan hasil dari masing-masing data kemudian dilakuan penarikan kesimpulan.

\section{HASIL DAN PEMBAHASAN}

Kabupaten Sleman yang merupakan bagian daerah dari Daerah Istimewa Yogyakarta mempunyak karakteristik wilayah atau Geografis terletak diantara $110^{\circ} 33^{\prime} 00^{\prime \prime}$ dan $110^{\circ} 13^{\prime} 00^{\prime \prime}$ Bujur Timur, $7^{\circ} 34^{\prime} 51^{\prime \prime}$ dan $7^{\circ}$ 
47' 30" Lintang Selatan. Wilayah Kabupaten Sleman sebelah utara berbatasan dengan Kabupaten Boyolali, Propinsi Jawa Tengah, sebelah timur berbatasan dengan Kabupaten Klaten, Propinsi Jawa Tengah, sebelah barat berbatasan dengan Kabupaten Kulon Progo, Propinsi DIY dan Kabupaten Magelang, Propinsi Jawa Tengah dan sebelah selatan berbatasan dengan Kota Yogyakarta, Kabupaten Bantul dan Kabupaten Gunung Kidul, Propinsi D.I.Yogyakarta(slemankab.go.id, 2021). Luas Wilayah Kabupaten Sleman adalah $57.482 \mathrm{Ha}$ atau $574,82 \mathrm{Km} 2$ atau sekitar $18 \%$ dari luas Propinsi Daerah Istimewa Jogjakarta 3.185,80 $\mathrm{Km} 2$ dan secara administratif terdiri 17 wilayah Kecamatan, 86 Desa, dan 1.212 Dusun(slemankab.go.id, 2021).

Dengan luas wilayah $18 \%$ dari luas Propinsi Daerah Istimewa Jogjakarta, Kabupaten Sleman mempunyai wilayah dataran rendah dan dataran tinggi dimana disebelah utara mempunyai Gunung Merapi dan tenggara ada pegunungan prambanan serta dataran rendah yang ada disebelah tengah dan barat, timur Kabupaten Sleman.Dengan potensi wilayah seperti itu maka Kabupaten Sleman mempunyai daya tarik bagi wisatawan untuk berkunjung karena mempunyai berbagai obyek wisata baik alam, budaya, pendidikan dan kuliner.

Disaat awal pandemi Covid-19 banyak kegiatan wisata menurun sehingga tingkat kunjungan wisatawan di obyek wisata mengalami penurunan atau sama sekali tidak ada pengunjung namun setelah pemerintah memperbolehkan obyek wisata disaat program kesehatan (prokes) menjadi protokol kesehatan yang harus wajib diaplikasikan memberi pengaruh obyek wisata untuk menawarkan wisata berbasis alam sebagai alternatif mengurangi kejenuhaan terlalu lama dirumah baik berdiam, bekerja dan belajar.

Banyak sekali obyek wisata di Kabupaten Sleman menawarkan Sport Tourism kepada wisatawan dimana wisatawan dapat berwisata dan berolahraga dapat menikmati keindahaan alam obyek wisata sekaligus berolahraga menyehatkan jasmani serta rohani akibat dampak pandemi Covid-19 yang belum reda. Potensi alam yang dimiliki Kabupaten Sleman dapat peneliti petakan sebagai destinasi wisata untuk kegiatan Sport Tourism dan melalui observasi dan berbagai sumber referensi maka dapat jelaskan dibawah ini.

\section{Bukit Klangon Cangkringan}

Obyek wisata ini sangat familiar bagi pengembar sepeda gunung atau mountain bike karena arena yang mendukung untuk olahraga sepeda gunung. Suasana yang dingin dan alam yang menantang banyak wisatawan menjajal obyek wisata ini, sehingga sering wisatawan yang suka sepeda gunung dengan tantangan alam yang bervariasi dan kadang agak ekstrim namun banyak yang menikmati wisata sport ini.

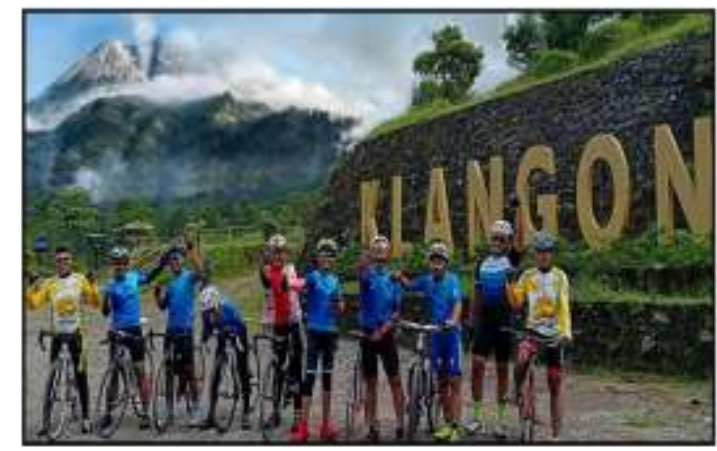

Sumber: WartaBegawan.net(2019)

Gambar 1. Aktivitas Mountain Bike di Bukit Klangon

Saat cuaca cerah wisatawan dapat menyaksikan puncak merapi yang tampak jelas kepundan dengan asap yang keluar daru kawah sehingga sangat mendukung sport tourism ini. Sejak dibuka untuk umum pada tahun 2011 yang lalu, Wisata Alam Bukit Glagaharjo, nama asli dari Bukit Klangon Merapi, menjadi salah satu wisata alam yang ramai kunjungan. Di sini juga seringkali diadakan kompetisi kejuaraan downhill sepeda MTB.

Melihat daya tarik alam yang menarik bukit klangon dan saat status Gunung Merapi normal tentunya wisata ini dapat mendukung kegiatan sport tourism dengan mengadakan event kejuaraan sepeda gunung, lomba lintas alam dan event olahraga lainnya. Dengan gunung yang masih aktif di dunia Gunung Merapi masih menjadi magnet bagi wisatawan luar negeri maka event-event internasional dapat diselenggarakan di obyek wisata ini.

\section{Kawasan Candi Prambanan}

Salah obyek wisata di Sleman yang paling terkenal di kancah pariwisata Internasional adalah Candi Prambanan sebagai kawasan wisata sejarah peradaban mataram Hindu obyek wisata ini sangat terkenal dengan wisata sejarah, pendidikan dan budaya. Dengan luas wilayah berhektar hektar sering kali obyek wisata ini digunakan untuk wisata 
sport. Banyak event wisata yang dibalut dengan wisata olah raga disini.

Banyak event-event nasional dan internasional kegiatan olah raga dan wisata yang diselenggarakan di dalam dan luar kompleks Candi Prambanan seperti Lari Marathon, Walk Heriitage, Yoga dan Sepeda Road Bike dan masih banyak lagi event-event wisata yang berbalut olahraga. Daya tarik obyek wisata Candi Prambanan ini adalah kawasan yang masih luas didukung bangunan candi yang bersejarah sehingga menarik orang datang untuk berwisata sekaligus berwisata. Seperti event Jalan Sehat mengitari kompleks Candi karena jalur pejalan kaki yang sudah disediakan sehingga setiap pagi dan sore banyak wisatawan berwisata dan berolahraga.

Disekitar kompleks Candi Prambanan suasana alam pedesaan yang masih asri seperti persawahaan dan kampung desa yang masih alami mendukung Sport Tourism diadakan di obyek wisata ini. Event yang selalu diselenggarakan di sekitar kompleks Candi Prambanan ini adalah Marathon bertaraf Internasional dimana pelari-pelari dari negara Asia, Eropa , AS dan Australia serta Afrika selalu berpartisipasi dalam acara tersebut. Dengan mengitari kompleks Candi Prambanan serta melewati pedesaan di sekitar Candi Prambanan para peserta sangat antusias mengikuti mereka puas dengan daya tarik yang mendukung kegiatan tersebut.

Kemudian event Sport Tourism yang paling banyak menyedot wisatawan datang ke Candi Prambanan adalah Olah Raga Sepeda baik sepeda santai maupun road bike. Untuk road bike biasanya diikuti pesepeda dari luar daerah dimana rute yang dijelajah sangat menarik dan menantang. Kegiatan yang dilakukan secara nasional ini biasanya mengambil rute star dan finish di kompleks Candi Prambanan dengan rute dataran tinggi di sekitar Gunung Merapi sehingga wisatawan sangat antusias menikmati event ini karena disuguhkan pemandangan alam yang alami serta kompleks Candi Prambanan yang mendukung kegiatan ini.

Sekitar Candi Prambanan juga didukung dengan suasana pedesaan menjadi daya tarik tersendiri bagi wisatawan untuk melakukan aktivitas olahraga di pagi dan sore dimana aktivitas kegiatan bersepeda baik secara individu maupun kelompok mewarnai pariwisata di obyek wisata Candi Prambanan. Kompleks yang luasnya berhektar-hektar serta suasana yang masih segar dan hijau mendukung aktivitas bersepeda di obyek wisata ini.

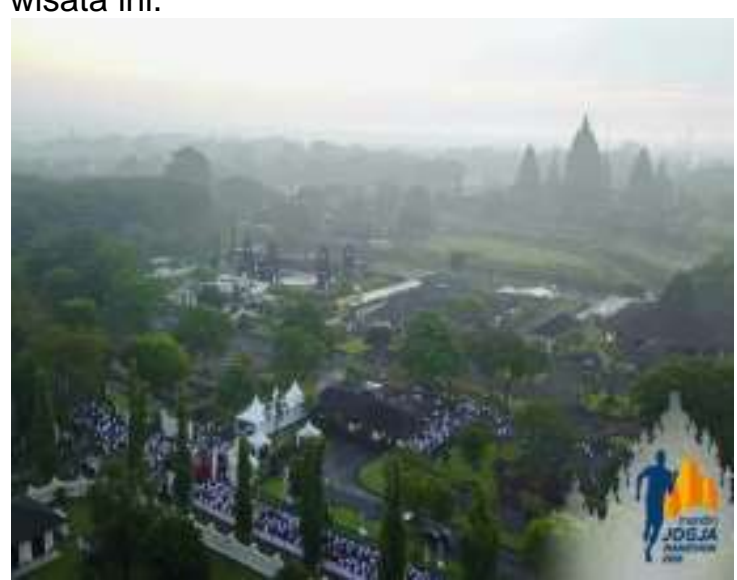

Sumber : Borobudurpark.com (2018)

Gambar 2. Kegiatan Marathon 2018 di

Candi Prambanan Sleman

Peran pengelola Candi Prambanan dalam hal ini PT Taman Wisata Candi Borobudur dan Prambanan dalam mendukung sport tourism sangat luar biasa dalam menyediakan fasilitas lokasi untuk event-event wisata olahraga baik dalam skala nasional dan internasional. Pemerintah Daerah Kabupaten Sleman selalu agenda tahunnya selalu mengadakan kegiatan di obyek wisata Candi Prambanan yang sudah terkenal sampai manca negara dan selalu sukses peserta dan penyelenggaraannya.

\section{Kawasan Aliran Sungai Progo}

Satu lagi kawasan wisata di Kabupaten Sleman yang mempunyai potensi wisata olah raga yang berbasis alam khususnya wisata air adalah kawasan aliran sungai progo yang ada di kecamatan Minggir dan Moyudan Kabupaten Sleman. Sungai Progo yang perbatasan dengan Kabupaten Kulon Progo di baratnya mempunyai potensi wisata air yang dapat dikunjungi wisatawan yaitu wisata olah raga arum jeram.

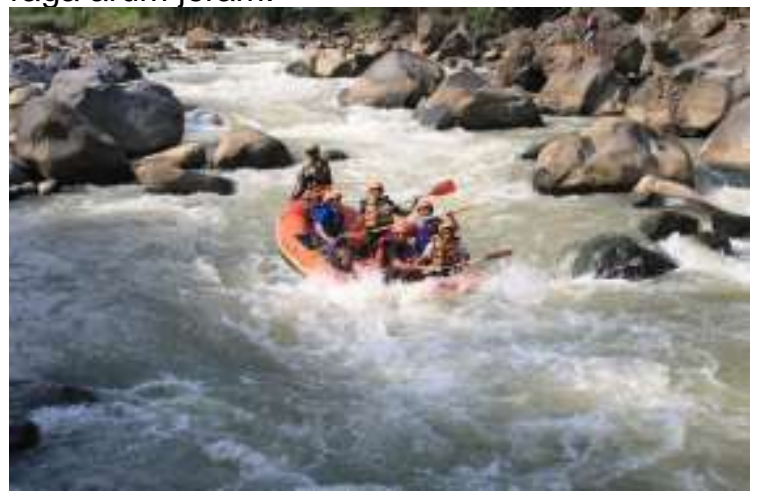

Sumber : koran-jakarta.com (2019)

Gambar 3. Wisata Arum Jeram di Sungai Progo 
Olah raga air ini banyak sekali yang berminat karena wisata yang seru dan menentang dan mempunyai graid kesulitan alirannya sehingga wisata ini cukup menentang karena arus sungainya yang deras dan bebatuannya yang masih banyak. Banyak operator yang menawarkan wisata ini dengan paket yang berragam ditawarkan dari pemula sampai yang senior. Mereka sudah berpengalaman dalam menghandle wisata arum jeram ini.

Selama mengikuti arung jeram wisatawan tidak hanya merasakan sensasi luar biasa dari derasnya aliran sungai namun dapat juga menikmati keindahan pemandangan di kanan kiri sungai yang masih alami. Terdapat bebatuan besar, tebing-tebing, serta pepohonan khas pinggiran sungai yang mungkin jarang kamu lihat. Di salah satu spot bahkan kamu bisa melihat air terjun yang cukup tinggi. Terhitung ada sekitar 5 jeram berukuran besar dan belasan lainnya berukuran kecil.

Ada kajian untuk rencana pengembangan sungai progo ini dilakukan Federasi Arung Jeram Indonesia (FAJI) Daerah Istimewa Yogyakarta salah satu hasil kajian adalah memanfaatkan aliran sungai progo menghasilkan tiga poin, yakni edukasi, prestasi, dan pariwisata. Salah satu pengembangan yang dilakukan adalah membangun white water stadium atau pusat olahraga arung jeram di aliran sungai progo yang mengalir di kabupaten Sleman dan Kulon Progo tersebut(koran-jakarta.com, 2019).

Jika itu terrealisasi tentu Kabupaten Sleman akan terdampak terutama masyarakatnya yang ada disepanjang sungai Progo dimana para wisatawan nusantara dan asing akan datang di kawasan aliran sungai progo untuk menikmati wisata olah raga air yaitu arum jeram sehingga dampak ekonomi memberi kesejahteraan warganya.

\section{Kawasan Perbukitan Kecamatan Prambanan Kabupaten Sleman}

Potensi wisata olah raga atau sport tourism di Sleman ada di daerah Kecamatan Prambanan dimana kawasan perbukitan mempunyai potensi wisata tersebut didukung obyek wisata yang sudah terkenal di kalangan wisatawan. Kawasan perbukitan yang mempunyai obyek wisata untuk olahraga tersebut ada di desa Sambirejo dan Bokoharjo.

Kawasan perbukitan di desa tersebut sangat cocok untuk wisata olahraga seperti lari lintas alam, bersepeda dan jalan sehat serta olah raga yang lain. Banyak event yang diselenggarakan dikawasan perbukitan tersebut.

Salah satu kegiatan olahraga yang sering diadakan adalah lomba lintas alam atau marathon dengan menyusuri perbukitan di desa sambirejo dimana wisatawan disuguhkan dengan pemandangan alam yang menarik dan alami. Start dan finish di obyek wisata Tebing Breksi dimana wisatawan diberi pemandangan potensi wisata alam yang menarik. Potensi wisata alam ini menawarkan banyak hal yang tidak boleh dilewatkan, diantaranya adalah pemandangan dinding tebing dengan ornamen patahan yang terlihat begitu artistic dan tebing ini memang sudah terbentuk jutaan tahun yang lalu dan dijadikan sebagai bekas tempat penambangan. tapi sisa-sisa dari aktivitas penambangan tersebut mampu menghadirkan ornamen pahatan yang membuat tebing tersebut tampak seperti kue lapis.

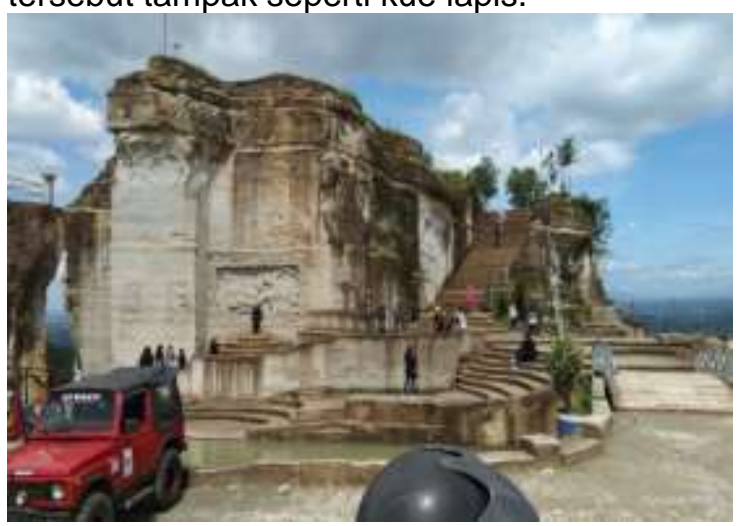

Sumber : data penelitian (2020)

Gambar 4. Obyek Wisata Tebing Breksi

Selain olahraga marathon wisatawan dapat melakukan aktivitas olah raga bersepeda sendiri dan bersama-sama dengan menjelajah perbukitan dengan pemandangan kota Yogyakarta disebelah barat dan Gunung Merapi di utara dan biasanya spot-spot wisata untuk foto setelah berolahraga sepeda menawarkan pemandangan tersebut.

Candi Boko sebagai situs peninggalan Mataram Hindu menawarkan pemandangan yang menarik selain candi juga lanskap wilayah Yogyakarta sehingga menarik wisatawan untuk berolahraga seperti jalan santai dan bersepeda di obyek wisata ini. Saat pandemi wisatawan sepeda banyak menjelajah perbukitan di prambanan salah satunya adalah obyek wisata Spot Riyadi yang ada di desa Sambirejo meski jalan yang menanjak namun para wisatawan tetap antusias berkunjung atau bersepeda karena banyak spot foto dengan latar belakang 
pemandangan yang menarik karena obyek wisata terletak diketinggian diantara obyek wisata yang lain.

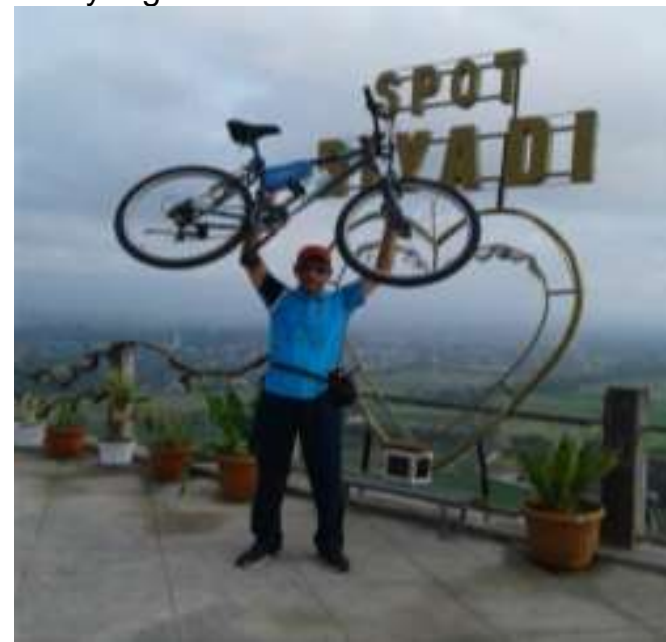

Sumber : Data Penelitian (2020)

Gambar 5. Seorang Wisatawan Pesepada di Obyek Wista Spot Riyadi

Pengembangan obyek wisata di wilayah perbukitan Kecamatan Prambanan mungkin lebih dapat dikembangkan untuk wisata olahraga dengan potensi pemandangan yang alami menjadi nilai plus dan mungkin banyak dibangun spot-spot wisata yang menarik wisatawan. Rute-rute yang menantang dapat ditawarkan kepada wisatawan untuk menjelajah perbukitan di kecamatan Prambanan misal event Marathon Alam, Sepeda Mountain Bike dan Jalan Sehat dan lainnya.

\section{Kawasan Aliran Sungai Opak}

Ada satu lagi kawasan wisata air yang dapat dikembangkan menjadi wisata olaraga berbasis air dimana Kabupaten Sleman dialiri sungai Opak yang ada di timur wilayah Kabupaten Sleman. Sungai opak yang bermata air di gunung Merapi dan berakhir di Laut Selatan DIY selalu mengalir deras meski musim kemarau tiba oleh karena itu banyak dimanfaatkan penduduk disepanjang aliran sungai tersebut.

Salah satu obyek wisata yang memanfaatkan aliran sungai Opak adalah wisata Lava Bantal yang ada di Kecamatan Berbah Kabupaten Sleman. Destinasi wisata ini menarik wisatawan karena ada peninggalan bersejarah berupa batu-batuan yang unik karena terbentuk dari lava yang membeku jutaan tahun yang lalu di sepanjang sungai opak di obyek wisata tersebut. Sehingga obyek wisata ini dikenal sebagai wisata pendidikan karena banyak sekalian wisatawan atau peneliti melakukan kunjungan bersifat belajar dan meneliti tentang batuan yang mempunyai sejarah geologi yang tinggi.

Pengelola akhirnya mengembangkan obyek wisata lebih lengkap lagi peran serta kelompok Sadhar Wisata di desa Jogotirto yang wilayahnya ada obyek wisata Lava Bantal menjadikan destinasi wisata ini dikembangkan menjadi wisata air seperti river tubing atau menyusuri aliran sungai Opak dengan star atau finish di obyek wisata ini.

Saat sebelum pandemic Covid 19 ini melanda obyek wisata ini sangat ramai dikunjungi untuk menikmati aliran sungai Opak dengan cara river tubing yang dikelola oleh kelompok sadhar wisata di obyek wisata Lava Bantal. Sebagai olah raga air wisata river tubing menjadikan aliran sungai opak di obyek wisata ini menjadi lebih hidup sehingga memberi pengaruh kesejahteraan ekonomi warga di sekitar obyek wisata ini.

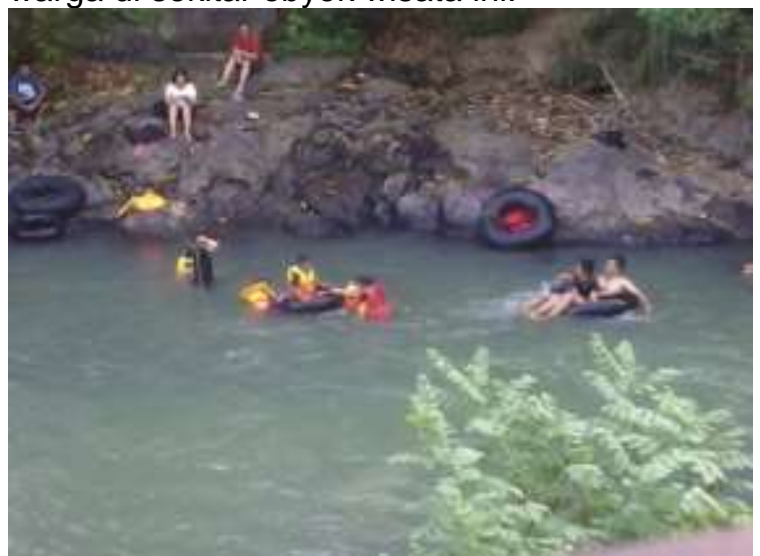

Sumber : Data Penelitian (2017)

Gambar 6. Aktivitas Wisata Olar Raga Air

River Tubing di Obyek wisata Lava Bantal Sebelum Pandemi Covid 19 melanda

Pada saat pandemi Covid-19 ini obyek wisata ini ramai dikunjungi wisatawan bersepeda baik secara individu maupun kelompok karena daya tarik sungai opak yang menarik sehingga wisatawan yang bersepeda tersebut menikmati pemandangan alam sungai Opak. Menurut pengamat peneliti selama melakukan penelitian di obyek wisata Lava Bantal dengan faktor wisata yang terbuka tempatnya dan didukung pengelola wisata yang professional obyek wisata aman dikunjungi dan sampai sekarang masih menjadi tujuan wisata pesepeda untuk berkunjung di obyek wisata ini.

Demikian uraian pemetaan obyek wisata atau kawasan wisata di Kabupaten Sleman yang kaya akan potensi wisata olah raga atau 
Sport Toursim dimana ada kawasan yang sudah dikelola dengan baik atau belum namun melihat data pustaka baik lewat media cetak, elektronik dan sosial ternyata obyek wisata tersebut menarik dikunjungi. Pemetaan obyek wisata ini penting sekali untuk memberi sumbangsih kepada pemerintah Kabupaten Sleman memberi perhatian lebih kepada pengelola wisata atau warga yang mengelola wisata tersebut agar dikembangkan lebih sehingga saat pandemic Covid-19 yang masih melanda dunia obyek wisata tetap bertahan sehingga ekonomi warga tetap terjaga kesejahteraannya.

\section{PENUTUP}

Hasil penelitian yang kami uraikan diatas dapat ditarik simpulan bahwa potensi wisata alam di Kabupaten Sleman telah banyak dikembangkan menjadikan wisata olah raga atau Sport Tourism yang berkembang dengan baik. Faktor daya tarik menjadikan wisatawan melakukan aktivitas Sport Tourism sebagai kebutuhan disaat pandemic Covid-19 masih melanda dunia ini. Untuk itu potensi alam di Kabupaten Sleman dapat dipetakan bahwa kawasan Gunung Merapi tempatnya dibukit Klangon Cangkringan sangat cocok sebagai destinasi wisata Mountain Bike atau sepeda gunung yang dapat digunakan untuk event kejuaraan nasional dan internasional. Kemudian kawasan wisata Candi Prambanan mempunyai potensi wisata olahraga berupa Lari Marathon, yoga dan Sepeda Road Bike maupun sepeda santai dengan dukungan kawasan sekitarnya yang masih alami. Selain candi ada kawasan wisata air di Kabupaten Sleman yang bisa mendukung wisata olah raga atau Sport Tourism yaitu aliran sungai Progo dimana kegiatan arum jeram sudah berkembang sejak lama dan daya tarik pemandangan alam menjadikan wisatawan tertarik untuk berolahraga arum jeram. Kemudian wisata air lainnya adalah obyek wisata Lava Bantal dimana obyek ini mengalir sungai opak yang dimanfaatkan untuk olah raga River Tubing yang dikelola kelompok sadhar wisata setempat. Kemudian potensi wisata alam lainnya kawasan perbukitan dikecamatan prambanan yang banyak obyek wisata untuk kegiatan sport tourism seperti Candi Boko, Tebing Breksi dan Spot Riyadi dan masih banyak lagi yang sering digunakan untuk wisata Marathon, Lintas alam dan Sepeda karena banyak spot yang menarik wisatawan didukung pemandangan dari ketinggian bisa melihat landscap Yogyakata dan sekitarnya

Dari kesimpulan diatas maka dapat peneliti memberi saran kepada pemerintah, pengelola dan masyarakat serta pelaku wisata bahwa Kabupaten Sleman Yogyakarta yang mempunyai potensi wisata alam yang dapat dikembangkan lebih luas lagi untuk wisata olah raga atau Sport Toursim. Masih banyak tempat di wilayah Kabupaten Sleman yang bisa dipetakan untuk kegiatan wisata ini misalnya wilayah perbukitan di Kecamatan Prambanan layak untuk pengembangan wisata olah raga lebih baik dan mungkin menjadi pusat kegiatan wisata olah raga untuk wilayah Yogyakarta misal wisata lari lintas alam atau marathon, mountain bike dan jelajah wisata dengan olah raga jalan kaki atau sepeda. Itulah saran dari peneliti untuk pengembangan potensi wisata alam di Kabupaten Sleman menjadi daya tarik wisata olah raga atau sport tourism. Untuk itu kedepan peneliti akan melakukan kajian tentang dampak-dampak kegiatan sport tourism di destinasi obyek wisata yang bersifat alam terhadap pengaruh kesejahteraan ekonomi warga masyarakat yang menjadi pelaku wisata atau pengelola wisata tersebut.

\section{DAFTAR PUSTAKA}

Anonim. Undang Undang tentang Kepariwisataan, UU No. 10 Tahun 2009. Jakarta: Direktorat Jenderal Hukum dan HAM .

Anonim. Undang-Undang Republik Indonesia Nomor 3 Tahun 2005 tentang Sistem Keolahragaan Nasional. Jakarta: Direktorat Jenderal Hukum dan HAM .

H. Kodhyat. 1998. Sejarah Pariwisata dan Perkembangannya di Indonesea. Jakarta. Grasindo

Kariza Devia Gantini HP dan Diyah Setiyorini, 2012. Pengaruh Revitalisasi Produk Wisata Terhadap Preferensi Mengunjungi Lembah Bougenville Resort (Survei pada Pengunjung Lembah Bougenville Resort Kecamatan Lembang Kabupaten Bandung Barat). Tourism and Hospitality Essentials (THE) Journal, Vol.II, No.2, 2012.

Moeloeng.L.J. 2003. Metodologi Penelitian Kualitatif. Bandung : Remaja Rodakarya 
Nurida Finahari1), Gatut Rubiono2), Ikhwanul Qiram3). Analisis Potensi Tari Gandrung Banyuwangi Sebagai Tarian Wisata Olahraga (Sport Tourism) . Prosiding Seminar Nasional IPTEK Olahraga, 2019, ISSN 2622-0156 Fakultas Olahraga dan Kesehatan, Universitas PGRI Banyuwangi Pariwisata

Nyoman.1998.Pengantar

Sukardi, Pariwisata..Denpasar: STP Nusa Dua Bali.

Silitonga, Marihot dan Anom, I Putu. 2016. Kota Tua Barus Sebagai Daerah Tujuan Wisata Sejarah Di Kabupaten Tapanuli Tengah. Jurnal Destinasi Pariwisata, Vol. 4 No 2, 2016.
Yoeti, Oka A. 2009. Pemasaran Pariwisata Terpadu. Bandung: Angkasa.

Pemerintah Kabupaten Sleman, 2006, Letak Dan Luas Wilayah Kabupaten Sleman. http://www.slemankab.go.id, diakses tanggal 27 Juni 2021

Wartabengawan, 2019, Gowes Ke Bukit Klangon Yang Menentramkan Hati, https://wartabengawan.net diakses tanggal 18 Juli 2021.

Media Taman Wisata Candi, 2018, Ribuan Pelari Ramaikan Mandiri Jogya Marathon 2018 Di Candi Prambanan, https://borobudurpark.com diakses tanggal 22 Juli 2021. 